\title{
Perception of Benefit and Barrier of Staff Education's Faculty of Medicine, Public Health and Nursing Gadjah Mada University with the Intention the Support toward Health Promoting University
}

\section{Persepsi manfaat dan hamatan tenaga kependidikan FK-MKM Universitas Gajah Mada dengan intesi dukungan terhadap health promoting university}

\author{
Harnianti $^{1}$, Yayi Suryo Prabandari ${ }^{2}$, Nur Juliana ${ }^{3}$ \\ 1Politeknik Karya Persada Muna \\ ${ }^{2}$ Universitas Gadjah Mada \\ ${ }^{3}$ Politeknik Karya Persada Muna
}

\begin{abstract}
Baground: Health promoting university (HPU) is a place to create a context of promoting health that is common in universities. This research aims to know the general picture of perception of education personnel FK-KMK UGM about the development of health promoting university.

Method:This type of research is quantitative with cross sectional study design. Bivariate analysis of research results using chi square and multivariate using logistic regression.

Results: The benefits of HPU according to tendik is to have policies relevant to the development of HPU, namely the prohibition of smoking, the availability of access to clean drinking water, the availability of bicycle routes to support physical activity, the environment supports physical activity, the availability of healthy canteens. HpU barriers according to tendik, namely the number of unhealthy foods and KTR policy has not been effective. Tendik FK-KMK UGM has a high intention to support the development of HPU. There is a significant relationship between benefits, with the intention of supporting the development of HPU with a value of $p=0.00$. There is a significant relationship between obstacles and the intention of supporting the development of HPU with a value of $p=0.005$.

Conclusions:The perception of FK-KMK UGM education staff about hpu development requires a domain of improvement on less effective policy barriers and facilities on campus are underutilized.

Keywords: health-promoting university, perceptions, benefits, barriers, intentions, education staff
\end{abstract}

\section{Abstrak}

Pendahuluan: Health promoting university (HPU) adalah tempat untuk menciptakan konteks mempromosikan kesehatan yang bersifat umum di universitas. penelitian ini bertujuan mengetahui gambaran umum persepsi tenaga kependidikan FK-KMK UGM tentang pengembangan health promoting university.

Metode: Jenis penelitian adalah kuantitatif dengan rancangan cross sectional study. Analisis hasil penelitian secara bivariat menggunakan chi square dan multivariat menggunakan regresi logistik.

Hasil: Manfaat HPU menurut tendik adalah memiliki kebijakan yang relevan dengan pengembangan HPU, yaitu larangan merokok, tersedianya akses air minum bersih, tersedianya rute sepeda untuk penunjang aktivitas fisik, lingkungan mendukung aktivitas fisik, tersedianya kantin sehat. Hambatan HPU menurut tendik, yaitu masih banyaknya makanan tidak sehat dan kebijakan KTR belum efektif. Tendik FK-KMK UGM memiliki intensi yang tinggi mendukung pengembangan HPU. Terdapat hubungan yang signifikan antara manfaat, dengan intensi mendukung pengembangan HPU dengan nilai $p=0.00$. Terdapat hubungan yang signifikan antara hambatan dengan intensi mendukung pengembangan HPU dengan nilai $p=0.005$.

Kesimpulan: Persepsi tenaga kependidikan FK-KMK UGM tentang pengembangan HPU membutuhkan domain perbaikan pada hambatan kebijakan yang kurang efektif dan fasilitas yang ada di kampus kurang dimanfaatkan.

Kata kunci: health promoting university, persepsi, manfaat, hambatan, intensi, tenaga kependidikan

Alamat Korespondensi:

Harnianti

Email : harnianti@gmail.com

Program Studi Promosi Kesehatan, Politeknik Karya Persada Muna 


\section{PENDAHULUAN}

Health promoting university (HPU) adalah tempat yang istimewa untuk menciptakan konteks mempromosikan kesehatan yang bersifat umum sehingga dapat meningkatkan profil kesehatan di universitas melalui pengembangan pendidikan, penelitian dan berbagai disiplin ilmu pengetahuan yang berkontribusi terhadap kesejahteraan dan keberlanjutan komunitas secara komprehensif dan juga dapat mengevaluasi efektivitas program intervensi (WHO, 1986). University of Central Lancashire menjadi salah satu dari beberapa universitas pertama di Eropa yang memiliki prakarsa promosi kesehatan diuniversitas ketika ditunjuk sebagai koordinator pada tahun 1995 (Dooris, 2001). Cina telah menerapkan konsep health promoting university sejak tahun 1997 dan berkembang sampai tahun 2000 dengan beberapa kebijakan, yaitu: mengontrol rokok, kesehatan mental, pencegahan penyakit menular, aktivitas fisik, dan pola konsumsi makanan sehat (Suárez-Reyes et al., 2016).

Pada tahun 2008, salah satu universitas di ASEAN, yaitu Universitas Gadjah Mada, telah mendeklarasikan diri dengan ditetapkannya Peraturan Rektor Universitas Gadjah Mada Nomor 29/P/SK/HT/2008 tentang Kawasan Tanpa Rokok di Universitas Gadjah Mada Yogyakarta yang awalnya diamanahi oleh traktat internasional FCTC (Framework Convention on Tobacco Control) dan adanya peraturan Indonesia yang menyatakan bahwa tempat pendidikan adalah kawasan bebas asap rokok (Universitas Gadjah Mada, 2008). Penetapan Peraturan Rektor tersebut diperkuat dengan hasil penelitian lain yang menyatakan bahwa pelaksanaan kebijakan kampus bebas rokok memiliki dampak positif pada pengurangan perilaku merokok dan menaikkan tingkat pengetahuan tentang bahaya merokok terbukti efektif menurunkan prevalensi perokok dari 4,8\% (2003) menjadi 3,2\% (2007), setelah deklarasi kampus bebas rokok pada tahun 2004 (Soh, 2015). Kebijakan lain yang sudah tertulis dalam Peraturan Rektor Universitas Gadjah Mada Nomor 6 Tahun 2016 adalah tentang pengelolaan kantin di lingkungan UGM. Kebijakan ini bertujuan untuk mensyaratkan para penjamu makanan yang berjualan di lingkungan UGM untuk mengikuti pelatihan pengolahan kantin sehat secara rutin (Universitas Gadjah Mada, 2016). Layanan sepeda kampus dan lahan parkir yang mendukung aktivitas fisik di lingkungan kampus tertuang dalam Peraturan Rektor Universitas Gadjah Mada Nomor 1/P/SK/HT/2015 tentang Kedudukan, Fungsi, dan Tugas Organisasi di Lingkungan Universitas Gadjah Mada (Universitas Gadjah Mada 2015). Hasil penelitian lain menunjukkan bahwa aktivitas fisik secara teratur mengurangi risiko beberapa penyakit kronis, termasuk hipertensi dan diabetes mellitus (Jeniper et al., 2004).

Universitas Gadjah Mada bergabung dengan Asian University Network untuk merumuskan health promotion network (AUN-HPN) untuk merumuskan kerangka konsep health promoting university menuju universitas sehat (healthy university). Berdasarkan kerangka konsep yang telah disusun, terdapat 7 strategi promosi kesehatan yang diterapkan di universitas yaitu implementasi program literasi kesehatan, kesehatan mental dan manajemen stres, keterikatan dan stimulasi sosial, aktivitas fisik dan mobilitas aktif, meningkatkan pola makan sehat dan gizi seimbang, pendidikan kesehatan reproduksi dan perilaku, serta kesehatan tempat kerja (AUN-HPN, 2017). Persepsi tendik tentang health promoting university dapat dijelaskan dalam teori perilaku yaitu Health Belief Model (HBM).

Teori Health Belief Model (HBM) adalah teori perilaku yang digunakan dalam penelitian untuk mengeksplorasi persepsi tenaga kependidikan FK-KMK UGM tentang pengembangan health promoting university dengan menilai beberapa komponen yang ada dalam HBM, yaitu persepsi manfaat, persepsi hambatan dan intensi dalam mendukung pengembangan health promoting university (Glanz et al., 2008). Aspek healthy university yang telah diterapkan di FK-KMK UGM mencakup fasilitas dan layanan (kantin sehat, sarana olahraga, stasiun sepeda dan tempat parkir, akses ke pelayanan kesehatan), kebijakan 
(kesetaraan dan keberagaman, kebijakan kesehatan), lingkungan (etos universitas, kebersihan dan keselamatan, bangunan dan penghijauan kampus) (Holt et al., 2015).

Pengembangan health promoting university, perlu adanya penelitian dengan mengidentifikasi konsep manfaat health promoting university (Holt et al., 2015). Konsep tersebut sudah dapat diterima dengan baik atau belum, sehingga penelitian tersebut dapat membantu melakukan evaluasi program terkait dengan hambatan-hambatan yang dirasakan dan manfaat dari health promoting university. Penelitian lain yang mendukung menunjukkan bahwa hambatan pengembangan health promoting university adalah belum adanya dana khusus yang digunakan untuk pengembangan program kesehatan di setting universitas, sehingga program mewujudkan universitas sehat dapat berkelanjutan dalam pengembangan healthy universities (Dooris et al., 2010).

Dalam melakukan pengembangan health promoting university perlu adanya identifikasi, tidak hanya pada mahasiswa tetapi juga pada tenaga kependidikan, untuk mengetahui persepsi tentang manfaat, persepsi tentang hambatan dan intensi dukungan tentang pengembangan health promoting university yang nantinya akan menjadi bahan evaluasi perbaikan dari pengembangan program health promoting university di FK-KMK UGM. Pemahaman dan respon sivitas akademika, khususnya tenaga kependidikan FK-KMK UGM, tentang pengembangan health promoting university masih beragam. Sasaran health promoting university adalah seluruh masyarakat universitas yang terdiri dari mahasiswa, staf, dosen dan masyarakat sekitar universitas yang bertujuan untuk meningkatkan kesehatan mahasiswa, karyawan universitas dan komunitas luas (Fertman, 2010).

Oleh karena itu, peneliti tertarik melakukan penelitian tentang persepsi tenaga kependidikan (tendik) FK-KMK UGM mengenai persepsi manfaat, persepsi hambatan dan intensi mendukung health promoting university yang nantinya sebagai bahan masukan dari Universitas Gadjah Mada yang sedang mengembangkan universitas menjadi universitas yang sehat.

\section{METODE PENELITIAN}

Jenis penelitian adalah kuantitatif menggunakan desain penelitian cross sectional. Variabel bebas (independent variable) pada penelitian ini adalah manfaat dan hambatan tentang health promoting university dan variabel terikat (dependent variable) adalah intensi dalam mendukung pengembangan health promoting university.

Populasi dalam penelitian adalah semua tenaga kependidikan FK-KMK UGM yang berasal dari 31 departemen FK-KMK UGM.Jumlah sampel dalam penelitian ini sebayak 84 responden dengan teknik pengambilan sampel menggunakan random sampling.

Analisis dalam penelitian ini menggunakan analisis univariabel, bivariabel dan anailisis multivariabel, analisis univariabel dilakukan untuk mengetahui distribusi dan frekuensi, analisis bivariabel dilakukan dengan menggunakan uji chi square dan analisis multivariabel menggunakan uji regression logistic.

\section{HASIL PENELITIAN}

\section{Univariabel}

Tabel 1 distribusi karakteristik responden tenaga kependidikan FK-KMK UGM menunjukkan bahwa dari 84 tendik, proporsi jenis kelamin tendik lebih dominan pada kelamin perempuan sebesar 55,95\%. Proporsi umur 20-40 tahun dan 41-60 tahun memiliki distribusi yang sama, yaitu sebesar $50,00 \%$. Proporsi tingkat pendidikan tendik lebih dominan berpendidikan S1 sebesar $44,05 \%$. 
Tabel 1. Distribusi karakteristik responden tenaga kependidikan FK-KMK UGM (bulan Maret 2019, $n=84$ )

\begin{tabular}{ccc}
\hline $\begin{array}{c}\text { Karakteristik } \\
\text { responden }\end{array}$ & $\begin{array}{c}\text { Frekuensi } \\
\text { (n) }\end{array}$ & $\begin{array}{c}\text { Persentase } \\
\text { (\%) }\end{array}$ \\
\hline $\begin{array}{c}\text { Jenis kelamin : } \\
\text { Laki-laki }\end{array}$ & 37 & 44,05 \\
Perempuan & 47 & 55,95 \\
\hline Umur : & & \\
20-40 th & 42 & 50,00 \\
41-60 th & 42 & 50,00 \\
\hline Pendidikan : & & \\
SMA & 28 & 33,33 \\
D3 & 19 & 22,62 \\
S1 & 37 & 44,05 \\
\hline
\end{tabular}

(Data Primer, 2019)

Tabel 2 menunjukkan distribusi frekuensi karakteristik responden berdasarkan variabel penelitian diketahui bahwa 57,14\% memiliki manfaat HPU yang tinggi, 72,62\% menganggap health promoting university memiliki hambatan tinggi, dan 51,19\% mayoritas tendik FK-KMK UGM memiliki intensi yang tinggi untuk mendukung pengembangan health promoting university.

Tabel 2. Distribusi karakteristik responden berdasarkan variabel penelitian pada tendik di FK-KMK UGM (bulan Maret 2019)

\begin{tabular}{ccc} 
Variabel & $\begin{array}{c}\text { Frekuensi } \\
(\mathrm{n})\end{array}$ & $\begin{array}{c}\text { Persentase } \\
(\%)\end{array}$ \\
\hline Manfaat : & & \\
Tinggi & 48 & 57,14 \\
Rendah & 36 & 42,86 \\
\hline Hambatan : & & \\
Tinggi & 61 & 72,62 \\
Rendah & 23 & 27,38 \\
\hline Intensi : & & \\
Tinggi & 43 & 51,19 \\
Rendah & 41 & 48,81 \\
\hline \multicolumn{2}{c}{ (Data Primer, 2019) }
\end{tabular}

(Data Primer, 2019)

Manfaat HPU menurut tendik berdasarkan hasil analisis univariat menyatakan bahwa HPU sangat bermanfaat, yaitu memiliki lingkungan kerja yang mendukung gaya hidup sehat, memiliki kebijakan yang relevan dengan pengembangan HPU, bermanfaat tersedianya sepeda layanan kampus untuk penunjang aktivitas fisik, memiliki akses yang mudah ke fasilitas layanan kesehatan, memiliki kantin sehat yang menyediakan makanan lokal, snack sehat dan murah, memiliki akses air minum bersih dan sehat, memiliki tanda larangan merokok di kampus, memiliki gedung yang aman dan ramah lingkungan, sehingga mendukung untuk bekerja, memiliki taman-taman di setiap fakultas, memiliki manajemen pengelolahan sampah dan daur ulang di kampus. 
Hambatan HPU menurut tendik berdasarkan hasil analisis univariat menyatakan bahwa hambatan health promoting university adalah masih banyaknya makanan tidak sehat seperti gorengan, tidak tersedianya akses fasilitas rekreasi seperti taman-taman, dan tidak adanya kebijakan di UGM yang mendukung kesehatan tendik.

Intensi tendik terhadap HPU menurut berdasarkan hasil anlisis univariat menunjukkan bahwa tendik memiliki intensi yang tinggi untuk mendukung UGM sebagai health promoting university, memiliki intensi tinggi tidak merokok di kampus, memiliki intensi tinggi akan menegur jika melihat seseorang merokok dalam kampus, memiliki intensi tinggi menjaga kesehatan diri sendiri sebagai berkontribusi penting dalam membangun universitas yang sukses dan sehat, memiliki intensi tinggi akan mengonsumsi makanan sehat di kampus, memiliki intensi tinggi akan memilih dan membeli makanan bersih dan sehat yang dijual di kampus, memiliki intensi tinggi akan mendukung kesehatan mental di kampus dengan menjaga diri agar tidak stres dalam proses bekerja, memiliki intensi tinggi akan melakukan konsultasi psikologis yang telah disediakan kampus agar saya terhindar dari masalah depresi, memiliki intensi tinggi akan memanfaatkan tempat parkir dan stasiun sepeda untuk dapat melakukan aktivitas fisik, memiliki intensi tinggi akan membuang sampah pada tempatnya, memiliki intensi tinggi apabila merokok, akan melakukan konsultasi berhenti merokok yang telah disediakan kampus.

\section{Bivariabel}

Tabel 3 menunjukkan hasil penelitian uji hubungan antara manfaat HPU dengan intensi mendukung pengembangan HPU menggunakan uji chi quare, menunjukkan bahwa terdapat hubungan antara variabel manfaat dengan intensi mendukung pengembangan health promoting university. Hasil analisis menggunakan uji chi square didapatkan nilai dan $p=0,000$. Artinya, bahwa secara statistik terdapat hubungan yang bermakna karena nilai $p<0,05$. Hal tersebut sesuai dengan hipotetsis penelitian bahwa terdapat hubungan antara manfaat HPU dengan intensi mendukung pengembangan HPU.

Tabel 3. Hasil uji hubungan variabel manfaat HPU dengan intensi mendukung pengembangan HPU pada tendik FK-KMK UGM

\begin{tabular}{ccccc}
\hline \multicolumn{4}{c}{ Intensi mendukung pengembangan HPU } \\
& & Rendah & Tinggi & P \\
\hline $\begin{array}{ccccc}\text { Manfaat } \\
\text { HPU }\end{array}$ & Rendah & 27 & 9 & \\
& Tinggi & 14 & 34 & 0,000 \\
\cline { 1 - 3 } Total & 41 & 43 & \\
\hline
\end{tabular}

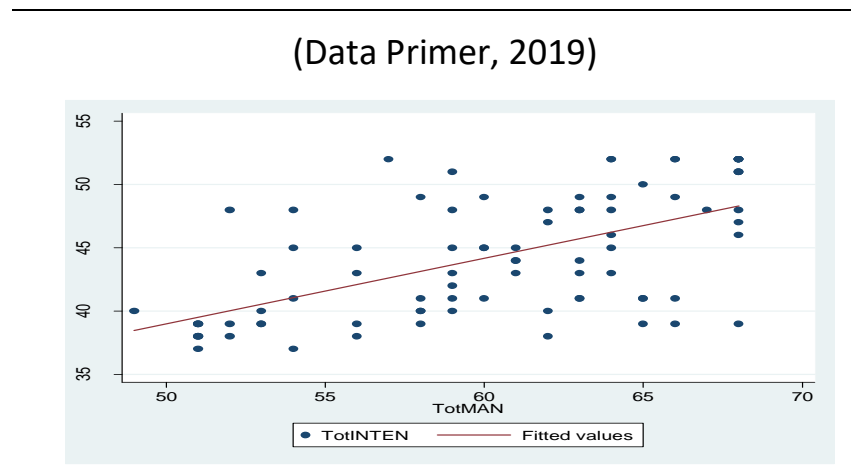

Gambar 1. Grafik scatter plot persepsi manfaat HPU dengan intensi mendukung pengembangan HPU

Tabel 4 menunjukkan hasil penelitian hubungan hambatan health promoting university dengan intensi mendukung pengembangan health promoting university, bahwa terdapat hubungan antara variabel 
hambatan dengan intensi mendukung pengembanganHPU. Hasil analisis menggunakan uji chi square didapatkan $p=0,005$. Artinya, bahwa secara statistik terdapat hubungan yang bermakna karena nilai $p<$ 0,05 . Hal tersebut sesuai dengan hipotesis penelitian bahwa terdapat hubungan antara variabel hambatan HPU dengan intensi mendukung pengembangan HPU.

Tabel 4. Hasil uji hubungan variabel hambatan HPU dengan intensi mendukung pengembangan HPU pada tendik FK-KMK UGM

\begin{tabular}{ccccc}
\hline \multicolumn{5}{c}{ Intensi mendukung pengembangan HPU } \\
\multicolumn{1}{c}{} & & Rendah & Tinggi & $\boldsymbol{p}$ \\
\hline Hambatan & Rendah & 17 & 6 & \\
HPU & Tinggi & 24 & 37 & \multirow{2}{*}{0,005} \\
\cline { 1 - 4 } \multicolumn{2}{c}{ Total } & 41 & 43 & \\
\hline
\end{tabular}

(Data Primer, 2019)

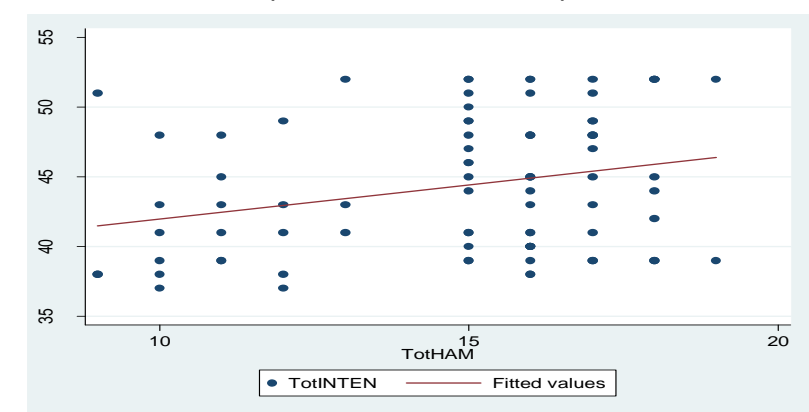

Gambar 2. Grafik scatter plot persepsi hambatan HPU dengan intensi mendukung pengembangan HPU

\section{Multivariabel}

Analisis multivariabel digunakan untuk mengetahui hubungan antara variabel manfaat health promoting university dengan intensi mendukung pengembangan health promoting university dengan mempertimbangkan variabel hambatan. Hasil analisis multivariabel menggunakan uji logistic regression dengan tingkat kemaknaan $p$-value $\leq 0,05$ pada tingkat kepercayaan 95\% dapat dilihat pada Tabel 5 .

Tabel 5. Hasil uji multivariabel

\begin{tabular}{lcc}
\hline Variabel & $\begin{array}{c}\text { Model 1 } \\
\text { Intensi }\end{array}$ & $\begin{array}{c}\text { Model 2 } \\
\text { intensi }\end{array}$ \\
\hline Manfaat & 1 & 1 \\
Rendah & $(1,1)$ & $(1,1)$ \\
Tinggi & $7,28 * * *$ & $8,45^{* * *}$ \\
& {$[2,74-19,37]$} & {$[2,93-24,35]$} \\
Hambatan & & 1 \\
$\quad$ Rendah & & $(1,1)$ \\
$\quad$ Tinggi & & $5.472^{* *}$ \\
$\quad$ & & {$[1,64-18,25]$} \\
N & 84 & 84 \\
Pseudo ${ }^{\sim} \mathrm{q}$ & 0,15 & 0,22 \\
AIC & 102,4 & 95,84 \\
\hline
\end{tabular}

${ }^{*} p<0.05, * * p<0.01, * * * p<0.001$ 
Hasil analisis multivariabel mendapatkan 2 model. Model 1 melihat pengaruh variabel manfaat terhadap intensi mendukung HPU dan mendapatkan nilai R2 sebesar 0,15 , yang menyatakan variabel manfaat memberikan kontribusi sebesar $15 \%$ terhadap intensi mendukung HPU.

Model 2 pada analisis melihat pengaruh antara variabel manfaat dengan variabel hambatan terhadap intensi mendukung pengembangan HPU dan mendapatkan nilai R2 sebesar 0,22, yang menyatakan variabel manfaat dan hambatan memberikan kontribusi sebesar $22 \%$ terhadap intensi mendukung pengembangan HPU.

\section{PEMBAHASAN}

\section{1) Persepsi tendik tentang manfaat health promoting university}

Persepsi tendik tentang manfaat health promoting university dalam penelitian bahwa health promoting university memiliki banyak manfaat salah satunya dengan adanya health promoting university merupakan suatu kesempatan mendapatkan promosi kesehatan. Kampus adalah tempat belajar dan bekerja bagi dosen dan tenaga kependidikan (Dooris et al., 2010). Oleh karena itu, universitas yang sehat memiliki dampak yang sangat positif dan akreditas yang baik jika memprioritaskan kesehatan dan kesejahteraan mahasiswa, staf, dan masyarakat luas.

Manfaat lain health promoting university berdasarkan hasil penelitian bahwa adanya kebijakan di UGM yang relevan dengan pengembangan health promoting university, seperti adanya tanda larangan merokok di tempat strategis di kampus. KTR atau pengaturan kebiasaan merokok merupakan salah satu intervensi dalam HPU (health promoting university). Penelitian lain yang mendukung menunjukkan bahwa implementasi KTR di FK-KMK UGM memberikan perubahan dalam kebiasaan merokok (Prabandari et al., 2013).

Manfaat selanjutnya yang didapatkan dari health promoting university menurut persepsi tendik berdasarkan hasil penelitian adalah adanya kebijakan lain tentang layanan sepeda kampus dan lahan parkir yang mendukung aktivitas fisik di lingkungan kampus, tersedianya akses air minum bersih dan segar di kampus, tersedianya upaya pencegahan penyalahgunaan narkoba dan alkohol, tersedianya gedung yang aman dan ramah lingkungan, sehingga mendukung untuk bekerja. Adanya lahan parkir yang didesain oleh kampus sebagai bentuk dari kebijakan kampus yang mendukung health promoting university, sehingga mengharuskan seluruh masyarakat kampus, khususnya tendik secara tidak langsung bertujuan mendukung untuk melakukan aktivitas fisik. Hal ini sejalan dengan penelitian yang dilakukan oleh Hikmawati (2018), bahwa health promoting university memiliki manfaat besar bagi kampus karena memiliki gedung kuliah aman, ramah lingkungan dan mendukung aktivitas fisik mahasiswa serta kampus memiliki taman-taman fakultas menurut mahasiswa sangat bermanfaat (Hikmawati, 2018). Penelitian lain yang mendukung bahwa universitas yang sehat akan memastikan bahwa setiap kebijakannya mendorong dan memberi insentif bagi mahasiswa, staf, dosen untuk menjadi sehat (Holt et al., 2015). Insentif ini dipahami mencakup penyediaan pilihan makanan sehat dan air minum gratis.

Manfaat health promoting university berdasarkan hasil penelitian adalah akses yang mudah ke fasilitas layanan kesehatan di kampus. Penelitian lain yang mendukung menunjukkan bahwa kebutuhan akan akses yang mudah dan efisien ke layanan kesehatan dianggap penting sebagai karakteristik untuk universitas yang sehat (Holt et al., 2015).

Manfaat lainnya adalah tersedianya rute sepeda untuk menunjang aktivitas fisik. Hasil penelitian lain yang mendukung menunjukkan bahwa aktivitas fisik secara teratur mengurangi risiko beberapa penyakit kronis termasuk hipertensi dan diabetes mellitus (Jeniper et al., 2004). Penelitian lain yang mendukung menyatakan bahwa program kesehatan telah diperkenalkan di tempat kerja di seluruh dunia untuk meningkatkan kesehatan dan kesejahteraan populasi fakultas, staf, dan mahasiswa yang hidup dan bekerja di lingkungan pendidikan tinggi yang bertujuan untuk mengurangi absensi dan 
rendah dalam premi asuransi kesehatan dan penciptaan tenaga kerja yang lebih sehat (Melnyk et al., 2016).

Manfaat selanjutnya menurut tendik tentang health promoting university adalah tersedia tempat parkir yang rapi dan tersedia fasilitas taman yang nyaman dan mudah di akses sebagai pelepasan stress saat bekerja. Penelitian lain yang sejalan menyatakan bahwa universitas yang sehat adalah universitas yang bersih, aman dan nyaman serta kebersihan menjadi prioritas untuk menuju universitas yang sehat, sehingga menjadikan institusi tersebut menjadi tempat yang aman untuk bekerja, tinggal dan belajar (Holt et al., 2015). Penelitian lain yang mendukung menyatakan bahwa kampus yang nyaman, ramah lingkungan, dan bebas polusi tentu tidak lepas dari adanya pohon-pohon yang menjadi salah satu indikator atau ciri kualitas lingkungan khususnya kampus (Hasibuan, 2018). Adanya pohon atau komunitas pohon tersebut tentu bernilai positif bagi lingkungan perkotaan seperti kampus, dengan melihat berbagai manfaat dari pohon, yaitu penghasil oksigen, penyerap polusi udara, peredam kebisingan, penyimpan air tanah, dan masih banyak lagi (Hasibuan, 2018). Manfaat HPU bertujuan untuk menciptakan universitas yang sehat. Universitas yang sehat memiliki dampak yang sangat positif dan akreditas yang baik jika memprioritaskan kesehatan dan kesejahteraan mahasiswa, staf, dan masyarakat luas (Dooris et al., 2010).

\section{2) Persepsi tendik tentang hambatan health promoting university}

Persepsi tendik tentang hambatan health promoting university dalam penelitian menunjukkan bahwa HPU memiliki hambatan paling besar terkait dengan fasilitas kampus, misalnya masih banyaknya makanan tidak sehat yang terjual di kantin.Kantin merupakan fasilitas kampus yang dibutuhkan oleh seluruh masyarakat universitas karena pengadaannya dianggap penting sebagai pengisi perut lapar dan juga tempat bercengkerama bersama teman dan kerabat. Salah satu syarat mutlak terjaminnya mutu kantin adalah kebersihan, kelayakan, dan kenyamanan. Oleh karena itu, kantin sehat memiliki nilai yang positif bagi institusi terutama universitas tidak hanya untuk memenuhi kebutuhan makanan dan minum tetapi juga mendorong masyarakat universitas untuk memilih makanan yang cukup dan seimbang. Penelitiaan yang mendukung menunjukkan bahwa makanan atau snack tidak sehat dan dapat berdampak buruk bagi kesehatan mereka (McArthur et al., 2017). Penelitian lain juga menunjukkan bahwa seharusnya kampus lebih memperhatikan penyediaan makanan dan minuman yang ada di kantin kampus karena berpengaruh pada pemilihan makanan (Hikmawati, 2018). penelitian lain yang mendukung bahwa akses ke makanan sehat dengan harga terjangkau di kampus merupakan fitur utama dan universitas yang sehat perlu memiliki kantin dengan pilihan makanan dan minuman sehat yang sesuai dengan kebutuhan semua orang, seperti rendah lemak, garam, gluten, dan gandum, selain pilihan makanan vegetarian sandwich dan salad dengan harga yang terjangkau (Holt et al.,2015).

Hambatan lain berdasarkan hasil penelitian adalah kurangnya fasilitas rekreasi di kampus seperti taman-taman. Hal tersebut didukung oleh penelitian lain, bahwa lingkungan universitas yang sehat dipengaruhi oleh etos universitas yang hangat dan ramah, lingkungan yang bersih dan nyaman untuk bekerja, lingkungan yang hijau, lokasi gedung baik, pencahayaan di dalam ruangan atau gedung yang baik dan memiliki cahaya matahari yang alami untuk meningkatkan rasa sejahtera (Holt et al., 2015).

Hambatan HPU selanjutnya adalah tentang fasilitas kesehatan kurang dimanfaatkan, sehingga berdampak negatif pada pengembangan HPU. Hal tersebut sejalan dengan penelitian lain, bahwa hambatan yang dirasakan untuk melakukan aktivitas fisik adalah kurangnya waktu (Silliman et al., 2004).

Persepsi tendik tentang hambatan yang dirasakan adalah dari segi kebijakan kampus mendukung HPU kurang efektif misalnya adalah tentang larangan merokok yang masih belum efektif. Hal tersebut didukung oleh penelitian lain bahwa perokok cenderung kurang menerima kebijakan TF (tobacco-free) di kampus karena kurang yakin dan merasa keefektifannya sedikit dirasakan (Ickes et al., 
2017). Penelitian lain yang mendukung bahwa tidak semua kebijakan yang ada di UGM mendukung kesehatan kemungkinan karena kurang merasakan dan menerima kebijakan UGM dalam pengembangan health promoting university (Hikmawati, 2018).

Penelitian lain yang mendukung menunjukkan bahwa dalam mengembangkan health promoting university, perlu adanya penelitian dengan mengidentifikasi konsep hambatan-hambatan yang dirasakan dari health promoting university (Holt et al., 2015).

\section{3) Intensi tendik mendukung pengembangan health promoting university}

Intensi tendik mendukung pengembangan health promoting university dalam penelitian memiliki intensi yang tinggi mendukung UGM sebagai health promoting university, misalnya tidak merokok di kampus dan akan menegur jika melihat seseorang merokok dalam kampus. Penelitian yang dilakukan oleh Sensussiana (2016 cit. Hikmawati 2018) bahwa melihat teman yang merokok merupakan salah satu faktor timbulnya keinginan seseorang untuk merokok akan lebih kuat dibandingkan dengan melihat orang lain yang tidak dikenal (Hikmawati, 2018).

Intensi tendik mendukung HPU adalah mengonsumsi makanan sehat di kampus, mendukung kesehatan mental di kampus dengan menjaga diri agar tidak stres dalam proses bekerja, memanfaatkan tempat parkir dan stasiun sepeda untuk dapat melakukan aktivitas fisik dan membuang sampah pada tempatnya. Penelitian yang mendukung menunjukkan bahwa pendidikan tinggi memiliki dampak yang sangat positif serta akreditas yang baik jika memprioritaskan kesehatan dan kesejahteraan mahasiswa, staf, dan masyarakat luas (Dooris, 2001). Penelitian yang mendukung menunjukkan, bahwa universitas yang sehat memiliki kebanggaan tersendiri jika memiliki tempat sampah dengan kualifikasi bermacammacam dan tidak memiliki area tempat merokok di lingkungan kampus dan juga lingkungan yang sehat perlu memperhitungkan faktor-faktor sosial, keuangan, mental, agama, etika, dan moral dari individu untuk menciptakan lingkungan yang harmonis dalam mendukung universitas sehat (Holt et al., 2015). Menurut University of Northern British Columbia (UNBC), staf, dosen dan mahasiswa memandang pengelolaan sampah dan daur ulang sebagai faktor utama untuk menghijaukan kampus (Booth, 2007 cit. Smyth, et al., 2010). Menurut penelitian yang dilakukan menujukkan bahwa upaya universitas mengembangkan HPU dipengaruhi oleh adanya kebijakan/aturan yang mendukung kesehatan dan adanya fasilitas kampus yang mendukung gaya hidup sehat seperti adanya GMC, sepeda kampus, lapangan olahraga, taman, bangunan aman, penyediaan air siap minum (Hikmawati, 2018). Hal tersebut akan mempengaruhi keputusan untuk mendukung HPU.

4) Hubungan antara manfaat health promoting university dengan intensi mendukung pengembangan health promoting university

Hubungan antara manfaat health promoting university dengan intensi mendukung pengembangan health promoting university, tendik mengangap bahwa kesehatannya sangat diperhatikan, sehingga kemungkinan cuti kerena sakit kecil, menghasilkan karyawan yang sehat sehingga produktivitas kerja meningkat, kampus bebas dari isu penyalahgunaan narkoba dan alkohol, menciptakan lingkungan sehat contohnya lingkungan bebas dari asap rokok, tersedia tempat parkir yang rapi dan tersedia fasilitas taman yang nyaman dan mudah diakses, dan meningkatkan derajat kesehatan masyarakat universitas, misalnya dengan danya deteksi dini pada pekerja dan adanya fasilitas penunjang kesehatan. Hal ini sejalan dengan penelitian mendukung, bahwa pemanfaatan tempat parkir dan stasiun sepeda untuk dapat melakukan aktivitas fisik terbukti mendorong niat mahasiswa untuk mendukung health promoting university (Hikmawati, 2018). Penelitian lain yang mendukung menujukkan bahwa dalam mengembangkan health promoting university, perlu adanya penelitian 
dengan mengidentifikasi konsep manfaat health promoting university (Holt et al., 2015). Konsep tersebut sudah dapat diterima dengan baik atau belum, sehingga penelitian tersebut dapat membantu melakukan evaluasi program. Penelitian Stephen Siu juga menyatakan bahwa konsep bangunan dan penghijauan kampus dapat diterapkan dengan ruang terbuka hijau salah satunya dengan konsep healing garden, yakni memaksimalkan fungsi taman yang berfungsi menenangkan dan memulihkan pikiran dari stress (Siu et al., 2014 cit. Hasibuan, 2018).

5) Hubungan antara hambatan health promoting university dengan intensi mendukung pengembangan health promoting university

Hubungan hambatan health promoting university dengan intensi mendukung pengembangan health promoting university, bahwa terdapat hubungan negatif persepsi tendik tentang hambatan health promoting university dengan intensi mendukung pengembangan health promoting university di FK-KMK UGM. Selain dari segi kebijakan, hambatan lain yang dirasakan tendik adalah dari segi fasilitas dan layanan kampus, contohnya masih adanya kantin di kampus yang kurang mendukung budaya hidup sehat misalnya masih banyak kantin yang menyediakan gorengan.

Penelitian yang mendukung menunjukkan bahwa persepsi mahasiswa cluster kesehatan UGM tentang health promoting university membutuhkan perbaikan pada domain hambatan, yaitu kantin yang belum mendukung gaya hidup sehat dan sistem akademik tidak mendukung kesejahteraan mahasiswa (Hikmawati, 2018). Dalam melakukan pengembangan health promoting university perlu adanya identifikasi, tidak hanya pada mahasiswa tetapi juga pada tenaga kependidikan, untuk mengetahui persepsi manfaat, persepsi hambatan dan intensi dukungan tentang pengembangan health promoting university yang nantinya akan menjadi bahan evaluasi perbaikan dari pengembangan program health promoting university di FK-KMK UGM.

Penelitian ini bisa menjadi bahan evaluasi kepada pimpinan terhadap pengembangan health promoting university tentang semua temuan yang menjadi hambatan dari segi kebijakan dan fasilitas yang diterapkan di kampus yang berdampak terhadap pengembangan HPU. Promosi kesehatan di setting universitas diharapkan semua masyarakat universitas dapat berpartisipasi dan ikut terlibat untuk mendukung pengembangan HPU tidak hanya mahasiswa, tetapi juga tenaga kependidikan karena universitas yang sehat adalah memiliki dampak yang sangat positif dan akreditas yang baik jika memprioritaskan kesehatan dan kesejahteraan mahasiswa, staf, dan masyarakat luas.

Penelitian ini bertujuan untuk mengeksplorasi persepsi tendik FK-KMK UGM tentang health promoting university dengan melihat dari segi manfaat dan hambatan dalam pengembangan health promoting university yang akan berdampak terhadap intensi untuk mendukung health promoting university menuju universitas sehat. Temuan dalam penelitian ini menyarankan bahwa pentingnya bagi tenaga kependidikan tidak hanya mahasiswa untuk terlibat dalam pengembangan health promoting university.

\section{KESIMPULAN}

1.) Persepsi tendik FK-KMK UGM tentang manfaat health promoting university menganggap sangat bermanfaat karena memiliki kesempatan untuk mendapatkan promosi kesehatan melalui health promoting university, adanya kebijakan di UGM yang relevan dengan pengembangan health promoting university, misalnya adanya tanda larangan merokok di tempat strategis di kampus, tersedianya gedung yang aman dan ramah lingkungan, sehingga mendukung untuk bekerja. Manfaat selanjutnya adalah tersedianya fasilitas penunjang hidup sehat, misalnya akses yang mudah ke fasilitas layanan kesehatan di kampus, tersedianya akses air minum bersih dan segar di kampus, tersedianya lahan 
parkir, rute sepeda, peta dan transportasi umum untuk penunjang aktivitas fisik, tersedia fasilitas taman yang mudah diakses sebagai pelepasan stres saat bekerja,

2.) Persepsi tendik FK-KMK UGM tentang hambatan health promoting university paling besar terkait dengan fasilitas kampus, misalnya masih banyaknya makanan tidak sehat yang terjual di kantin, senam sehat setiap Jumat masih banyak yang belum bisa mengakses fasilitas tersebut karena waktunya yang tidak sesuai dengan kegiatan akademik, kebijakan kampus mendukung HPU kurang efektif, misalnya tentang larangan merokok yang masih belum efektif yang dibuktikan dengan masih ada tendik yang merokok di kampus.

3.) Intensi tendik dalam mendukung pengembangan health promoting university adalah menjaga kesehatan mental agar tidak stres dalam bekerja, memanfaatkan fasilitas yang telah disediakan oleh kampus sebagai penunjang hidup sehat, mendukung lingkungan sehat dengan tidak menyediakan area tempat merokok di kampus dan membuang sampah pada tempatnya.

4.) Terdapat hubungan antara manfaat health promoting university dengan intensi mendukung pengembangan health promoting university, misalnya dengan adanya kebijakan yang relevan dengan pengembangan health promoting university dan fasilitas yang mendukung budaya hidup sehat dikampus maka akan mendorong niat tendik untuk hidup sehat.

5.) Terdapat hubungan antara hambatan health promoting university dengan intensi mendukung pengembangan health promoting university, misalnya adalah kebijakan dan fasilitas mendukung HPU kurang efektif, contohnya larangan merokok yang masih belum efektif yang dibuktikan dengan masih ada tendik yang merokok tentang waktu pelaksanaan senam rutin yang diadakan oleh kampus, sehingga program tersebut banyak yang tidak terlibat karena keterbatasan waktu, lingkungan yang kurang nyaman di tempat bekerja misalnya adalah banyaknya sampah yang belum termenejemen dengan baik. Selain dari segi kebijakan, hambatan lain yang dirasakan tendik adalah dari segi fasilitas dan layanan kampus, contohnya masih adanya kantin di kampus yang kurang mendukung budaya hidup sehat misalnya penyediaan makanan siap saji (indomie dan pop ice), masih banyak kantin yang menyediakan gorengan dan kurangnya ketersediahan buah-buahan dikantin. Hal tersebut dapat berdampak pada intensi tendik sehingga memiliki pola hidup tidak sehat dan berdampak pada kinerja tendik.

6.) Persepsi tenaga kependidikan FK-KMK UGM tentang health promoting university bahwa sehat adalah tidak terkena penyakit sehingga dapat melaksanakan aktivitas dengan lancar dan baik, pandangan tentang promosi kesehatan bahwa promosi kesehatan adalah suatu himbauan atau kebijakan universitas yang bertujuan untuk menjadikan lingkungan kampus sehat dan meningkatkan kesehatan seluruh masyarakat di universitas, sasaran HPU adalah semua masyarakat yang ada di universitas yang terdiri dari mahasiswa, staf, cleaning service, tenaga edukatif, pimpinan, perwakilan lintas dan pimpinan, manfaat HPU dapat menjadikan universitas menjadi universitas sehat, sehingga profil kempus meningkat, lingkungan sehat, dan derajat kesehatan masyarakat universitas meningkat, pengembangan HPU memiliki domain hambatan pada kebijakan kurang efektif, fasilitas dan layanan yang kurang dimanfaatkan, sikap yang kurang baik untuk mendukung HPU, dan HPU masih terdengar asing bagi tedik.

\section{DAFTAR PUSTAKA}

Asian University Network-Health Promotion Network (AUN-HPN). (2017). AUN Healthy University Framework. ISBN: 978-616-443047-1. AUN-Health Promotion Network, Mahidol University, Thailand. 
Dooris, M. (2001). The "Health Promoting University": A critical exploration of theory and practice. Health Education, 101(2), 5160. https://doi.org/10.1108/09654280110384108

Dooris, M., Cawood, J., Doherty, S., \& Powell, S. (2010). Healthy Universities: Concept, Model and Framework for Applying the Healthy Settings Approach within Higher Education in England. Final Project Report, 1-26. https://doi.org/10.1016/B978$\underline{0-12-289673-6.50011-7}$

Dooris, M., \& Doherty, S. (2010). Healthy universities - Time for action: A qualitative research study exploring the potential for a national programme. Health Promotion International, 25(1), 94-106. https://doi.org/10.1093/heapro/daq015.

Downes, L. (2015). Physical Activity and Dietary Habits of College Students. The Journal for Nurse Practitioners. Vol. 11. Issue 2.

Fertman, Carl I, Diane D Allensworth.2010. Health Promotion Programs: from theory to practice. Wiley. San Fransisco

Glanz, K., Rimer, B. K., \& Viswanath, K. (2008). Health Behavior and Health Education. https://doi.org/http://hdl.handle.net/2027/spo.10381607.0007.102

Hasibuan, T. A. (2018). Hubungan antara health literacy dengan sikap mahasiswa non kesehatan terhadap health promoting university di universitas Gadjah Mada. https://doi.org/thesis

Hikmawati, Z. (2018). Persepsi Mahasiswa Cluster Kesehatan UGM Tentang Health Promoting University. Universitas Gadjah Mada. https://doi.org/thesis

Holt, M., Monk, R., Powell, S., \& Dooris, M. (2015). Student perceptions of a healthy university. Public Health, 129(6), 674-683. https://doi.org/10.1016/i.puhe.2015.03.020

Ickes, M. J., Rayens, M. K., Wiggins, A., Hahn, E. J. 2017. Students' Beliefsabout and Perceived Effectiveness of a Tobacco-Free Campus Policy.Policy, Politics, \& Nursing Practice. Vol. 18(1) 17-25. Available at:https://doi.org/10.1177/1527154417700633

Jeniper, KC. (2004). The relationships among constructs in the health belief model and the transtheoretical model among AfricanAmerican college women for physical activity. American Journal of Health Promotion, 18(5), 354-357. Retrieved from http://search.ebscohost.com/login.aspx?direct=true\&db=rzh\&AN=106566507\&site=ehost-live

McArthur, L. H., Valentino, A., Holbert, D. (2017). Knowledge of Healthy Food Does Not Translate to Healthy Snack Consumption among Exercise Science Undergraduates. Nutrition and Health. Vol. 23 (2) 103-110.

Melnyk, B. M., Amaya, M., Szalacha, L. A., \& Hoying, J. (2016). Relationships Among Perceived Wellness Culture, Healthy Lifestyle Beliefs, and Healthy Behaviors in University Faculty and Staff: Implications for Practice and Future Research. Western Journal of Nursing Research, 38(3), 308-324. https://doi.org/10.1177/0193945915615238

Prabandari, Y. S., Ng, N., \& Padmawati, R. S. (2013). tembakau studi efektivitas penerapan kebijakan kampus bebas rokok terhadap perilaku dan status merokok mahasiswa di fakultas kedokteran UGM, .... Jurnal Manajemen Pelayanan Kesehatan, 12(4), 218-225. Retrieved from http://journal.ugm.ac.id/index.php/jmpk/article/view/2541

Smyth, D. P., Fredeen, A. L., Booth. A. L. (2010). Reducing Solid Waste in Higher Education: The First Step towards 'Greening' A University Campus. Resources, Conservation and Recycling 54 (2010) 1007-1016

Universitas Gadjah Mada. (2008). Peraturan Rektor Universitas Gadjah Mada Nomor 29/P/SK/HT/2008 tentang Kawasan Bebas Rokok. Retrieved from http://www.ugm.ac.id/

Soh, Chin Thing. (2015). Smoke-Free Campus Policy And Smoking Behavior - Comparison Of 2003 and 2007 FM UGM Student Survey. Yogyakarta : Universitas Gadjah Mada

Universitas Gadjah Mada. (2016). Peraturan Rektor Universitas Gadjah Mada Nomor 6 Tahun 2016 tentang Pengelolaan Kantin di Lingkungan Universitas Gadjah Mada. Retrieved from http://www.ugm.ac.id/

Universitas Gadjah Mada. (2015). Peraturan Rektor Universitas Gadjah Mada Nomor 1/P/SK/HT/2015 tentang Kedudukan, Fungsi, dan Tugas Organisasi di Lingkungan Universitas Gadjah Mada. Retrieved from http://www.ugm.ac.id/

Winslade, Matthew, \& Bradley, W. (n.d.). Wellbeing in Higher Education: Cultivating a Healthy Lifestyle Among Faculty ... - Google Buku. Retrieved December 12, from https://books.google.co.id/books?hl=id\&lr=\&id=rcZUDwAAQBAJ\&oi=fnd\&pg=PT135\&dq=Winslade, + Matthew, +and+Brad ley+Wright.+(2018).\%2210+Sport+and+exercise.\%22+Wellbeing+in+Higher+Education:+Cultivating+a+Healthy+Lifestyle+ Among+Faculty+and+Students\&ots=6pn4Hs2g 
World Health Organization. (1986). The Ottawa charter for health promotion. Ottawa: Canadian Public Health Association.

Suárez-Reyes, M., \& Van den Broucke, S. (2016). Implementing the Health Promoting University approach in culturally different contexts: a systematic review. Global Health Promotion, 23(October), 46-56. https://doi.org/10.1177/1757975915623933 